\title{
Development and psychometric validation of the Dispositional Recovery and Dysfunction Inventory: a tool to assess for positive and negative cognitions following trauma exposure
}

\author{
Brian A. Moore ${ }^{1,2,3 \star}$, Willie J. Hale ${ }^{3}$, Jason L. Judkins ${ }^{3,4}$ and Alan L. Peterson ${ }^{2,3,5}$ \\ ${ }^{1}$ Department of Psychological Science, Kennesaw State University, 1000 Chastain Road NW, Kennesaw, GA 30144, USA, \\ ${ }^{2}$ Department of Psychiatry and Behavioral Sciences, University of Texas Health Science Center at San Antonio, \\ 7550 IH-10 West, Suite 1325, San Antonio, TX 78229, USA, ${ }^{3}$ Department of Psychology, University of Texas at San \\ Antonio, 1 UTSA Circle, San Antonio, TX 78249, USA, ${ }^{4}$ United States Army Institute of Environmental Medicine Building \\ 42, General Greene Avenue, Natick, MA 01760, USA and ${ }^{5}$ Office of Research and Development, South Texas Veterans Health \\ Care System, 7400 Merton Minter Boulevard, San Antonio, TX 78229, USA \\ *Corresponding author. Email: Brian.Moore@Kennesaw.edu
}

(Received 2 November 2020; revised 21 February 2021; accepted 21 April 2021; first published online 31 May 2021)

\begin{abstract}
Background: Recovery from trauma can be naturally occurring or facilitated through psychotherapy. Few brief measures exist to provide clinicians with dispositional, empirical assessments of patient's sentiments during psychotherapy.

Aims: This manuscript presents the Dispositional Recovery and Dysfunction Inventory (DRDI), a measure created to assist clinicians in evaluating patient's treatment progress during psychotherapy, as well as evaluate its factor structure, reliability estimates, measurement invariance, and correlates.

Method: The DRDI was created based on feedback from experts with experience treating posttraumatic stress disorder (PTSD) and was structurally validated in two distinct populations. Exploratory factor analysis was conducted in sample 1 consisting of $(n=401)$ university students. Confirmatory factor analysis, measure validity and structure validation were then conducted in sample $2(n=249)$ composed of $49 \%$ individuals with clinically significant PTSD symptoms.

Results: Exploratory and confirmatory factor analysis revealed that the DRDI was best represented by a two-factor correlated traits model representing sentiments related to dispositional recovery and dysfunctional cognitions. The recovery subscale exhibited relationships with convergent measures including authenticity and psychological hardiness ( $r$ values of .30 to .60 ). The dysfunctional beliefs subscale exhibited relationships with convergent measures: PTSD, depression, suicidality and stress ( $r$ values of .55 to 80). Measurement invariance across gender and PTSD status was observed.

Conclusion: Initial findings indicate that the DRDI has the potential to be a useful tool to assess individuals' beliefs about their propensity to recover from and thrive through adversity.
\end{abstract}

Keywords: dysfunctional cognitions; factor analysis; post-traumatic stress disorder; recovery; resilience; trauma

\section{Introduction}

Most individuals experience trauma at some point during their lives (Benjet et al., 2016; Kilpatrick et al., 2013). Potentially traumatic experiences may range from natural disasters to robberies, automobile accidents, sexual assaults, combat/warzone exposure, and a host of other traumas

(C) The Author(s), 2021. Published by Cambridge University Press on behalf of the British Association for Behavioural and Cognitive Psychotherapies. This is an Open Access article, distributed under the terms of the Creative Commons Attribution licence (http:// creativecommons.org/licenses/by/4.0/), which permits unrestricted re-use, distribution, and reproduction in any medium, provided the original work is properly cited. 
(Kilpatrick et al., 2013). Individuals who are exposed to trauma or high levels of stress have differing coping abilities. Some individuals may be less affected and recover quickly, whereas others may recover more slowly and be at increased risk for developing a myriad of psychiatric disorders such as anxiety, depression, or posttraumatic stress disorder (PTSD). PTSD is a trauma and stress-related disorder that is characterized by a range of maladaptive reactions to the experiencing of a catastrophic stressor (American Psychiatric Association, 2013). Despite the high rates of trauma exposure in the general population, studies have shown the 12 month prevalence estimates of PTSD to be less than $5 \%$ in both the global and the US population (Kessler et al., 2005; Kilpatrick et al., 2013), indicating that healthy habituation and/or recovery is the predominant response to traumatic experiences.

Recovery is the return to normal pre-exposure functioning after elevated symptoms or dysfunction from subthreshold or threshold psychopathology or trauma exposure (Bonanno, 2004; Bonanno et al., 2011). The return to full recovery may be short-term or progress over months to years. There is a robust literature dedicated to examining factors that may facilitate recovery following exposure to traumatic events. Resilience, a distinctly separate but intermixed construct with recovery (Bonanno et al., 2002; deRoon-Cassini et al., 2010), is perhaps the most commonly described of these factors and has been found to be a protective factor against the impacts of trauma-related stress (Lee et al., 2016) and PTSD symptoms (Aiena et al., 2016; Lee et al., 2014; Stratta et al., 2015). Furthermore, resilience probably contributes to enhanced recovery. These findings have been shown in many varied populations to include survivors of childhood trauma and natural disasters as well as firefighters (Lee et al., 2014; Stratta et al., 2015; Wingo et al., 2010). In all, the current literature indicates that resilient individuals tend to be less negatively impacted by traumatic experiences. Despite this, recovery from trauma, and thereby resilience is likely a process that can be naturally occurring or facilitated through psychotherapy. As such, the present study was designed to address the call for additional formative research (see Schultze-Lutter et al., 2017) by developing a brief measure informed by experts in the treatment of trauma-based psychopathology. Little is known about the dynamic relationship between recovery, resilience, and dysfunction after trauma exposure.

\section{Conceptualizing and measuring recovery independent of resilience}

Currently, there is not a 'gold standard' amongst the published resilience measures (Windle et al., 2011). Most research describes resilience generally as an individual's ability to cope with or overcome exposure to adversity or stress (Meredith et al., 2011). Conversely, other research has proposed that resilience serves to help individuals learn and grow through adversity (Pargament and Cummings, 2010; Zautra et al., 2010). Regardless, the literature largely indicates that resilience is a malleable, multi-faceted construct that is dependent on an individual's environment, and life experiences (Broekman, 2011). As such, many of the existing measures of resilience have been created from this theoretical framework and broadly examine the propensity for positive reactivity to a variety of scenarios, examining elements of resilience as a binary construct (e.g. low resilience/high resilience [Connor and Davidson, 2003; Wagnild and Young, 1993], or low hardiness/high hardiness [Bartone, 2007]). We contend, however, that trauma and adversity rarely occur in isolation and that resilience is not explicitly, or necessarily bipolar. Thus, despite the proliferation of measures of resilience, existing measures serve to assess for resilience in the absence of the negative cognitive states that occur following trauma exposure and do not allow for the assessment of dysfunctional cognitions that may be holding a person back from recovery during psychotherapy. Indeed, Bonanno (2004) states that the relationships between resilience and dysfunction cannot be fully understood without consideration of intersectionality. This is the crux of recovery. More succinctly, most existing measures are unable to inform this debate because they only measure 
one element of the construct, thereby not accounting for the dispositional effect of negative cognitions/dysfunctional thoughts.

To examine whether the construct is truly bipolar, we conceptualized resilience from the recovery standpoint. That is to say that recovery is not only a dispositional factor per se, but also the result of a process. To address this, we put forth that if a measure of resilience, viewed through the lens of recovery, is to be helpful in the clinical environment then it needs to assess an individual's ability (or inability) to cope with trauma or adversity. In sum, resilience and recovery are both processes that cannot exist without adversity, and dysfunctional cognitions that arise from adversity do not simply disappear when an individual is 'resilient'. Furthermore, we posit that recovery and dysfunctional cognitions may not be differentially exclusive and are likely to involve separate correlates. To our knowledge, no measures explicitly assess recovery from this perspective.

\section{Correlates and invariance testing in existing measures of resilience}

Numerous studies have examined the relationships between trauma exposure and resilience, and have shown current measures of resilience to be inversely related to PTSD symptoms (Aiena et al., 2016; Pitts et al., 2016; Scali et al., 2012), anxiety and depression (Ristevska-Dimitrovska et al., 2015; Morote et al., 2017), suicidality (Bezdjian et al., 2015; Nrugham et al., 2010; Rossetti et al., 2017; Roy et al., 2011), substance use (Chmitorz et al., 2018), and mixed findings concerning social dysfunction (Chmitorz et al., 2018; Smith et al., 2008). Current measures have also shown resilience to be positively correlated with constructs such as authenticity (Di Fabio and Palazzeschi, 2015) and psychological well-being (Mayordomo et al., 2016; Rapport et al., 2019).

Studies examining gender invariance with current resilience measures present divergent findings, but largely it seems that males and females interpret resilience differently (Connor and Davidson, 2003; Liu et al., 2015; Pulido-Martos et al., 2019). As such, we believe that measurement invariance for gender must be examined and established to meaningfully examine the construct. Interestingly, despite the apparent agreement amongst the theoretical orientations that negative experiences are a requisite for resilience, to our knowledge, no empirically validated scales have examined scale invariance by PTSD status. Thus again, the current literature is unable to assess if individuals with PTSD experience or interpret resilience in the same manner as individuals who have habituated to trauma exposure in a healthy manner. Considering this, the present paper aims to (1) introduce a newly developed measure that can assist clinicians in assessing for progress in recovery as well as the persistence of dysfunctional cognitions in trauma exposed patients; (2) determine the factor structure of the Dispositional Recovery and Dysfunction Inventory (DRDI); (3) establish measurement invariance across gender and by PTSD diagnosis; (4) examine the correlates of the DRDI including psychosocial measures and measures of disorders commonly co-morbid with dysfunctional responses to trauma exposure; and (5) establish the predictive utility of DRDI scores.

\section{Method}

\section{Scale development: the Dispositional Recovery and Dysfunction Inventory}

The initial set of items considered for the DRDI were developed through an iterative process consisting of a focus group, held with experts in the research and treatment of PTSD and two follow-on surveys. This process was conducted to ensure precision in the sentiments related to the constructs of recovery and dysfunction, while simultaneously reducing the time burden on respondents. All focus group participants were affiliated with the 'South Texas Research Organizational Network Guiding Studies on Trauma And Resilience' (STRONG STAR) at the 
Table 1. Dispositional Recovery and Dysfunction Inventory Instructions: Below you will find below a series of statements, which may describe your personal feelings surrounding attributes or scenarios. Please use the scale below to describe to what extent each item is characteristic of you. Please circle a number (1 [not at all characteristic of me] to 7 [entirely characteristic of me]) that describes you best.

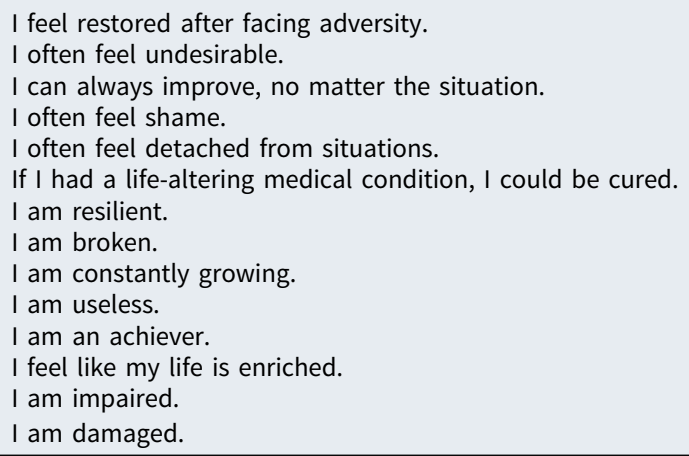

time the focus groups convened. The initial focus group $(n=8)$ consisted of five doctoral-level psychologists and three master's level researchers. During this focus group, participants were asked to describe the words or feelings they most commonly hear patients with PTSD use to describe themselves at pre-treatment (representative of dysfunctional cognitions) and again closer to the end of treatment (representative of resilient or recovery-related cognitions). The result of this focus group was a list of 30 positive and negative sentiments (15 each). To refine the list of stimuli, the list of participants in focus group 1 was expanded to include an additional 23 behavioural health professionals $(n=31)$.

Additional refinement of these stimuli was conducted via survey. Survey 1 had a $31 \%(n=10$ of 31) response rate, consisting of seven doctoral-level psychologists (PhD: $n=6$; PsyD: $n=1$ ) and three master's level researchers. Participants responded to the survey by ranking each provided sentiment by order of precedence (e.g. most frequently expressed sentiment, to least frequently expressed). The sum frequency of each response was combined and a final list of 10 sentiments was selected and emailed out to the same group a third time. Survey 2 was similarly survey based with a response rate of $26 \%$ ( $n=8$ of 31 ). Survey 2 respondents consisted of four doctoral-level psychologists (PhD: $n=3$; PsyD: $n=1)$, one doctoral level $(\mathrm{PhD})$ nurse, and three master's level researchers. Again, participants ranked the sentiments based on their most common experiences working with individuals with PTSD. The most frequently selected sentiments were selected to construct the final version of the measure, which is presented in Table 1.

\section{Data analytic plan}

The goal of Aim 2 was to determine the factor structure underlying the DRDI. To do this, we conducted exploratory and confirmatory factor analysis using Mplus software (version 7.2 software; Muthén \& Muthén, 2012) and verified the DRDI factor structure in two distinctly different samples. An MLR estimator was utilized to correct for potential non-normality in the data. The following criteria were utilized to evaluate model fit: (a) standardized factor loadings, (b) coefficient omega reliability estimates, (c) comparative fit index (CFI) value >.90, (d) root mean squared error of approximation (RMSEA) value <.08 ( $\mathrm{Hu}$ and Bentler, 1999; MacCallum et al., 1996); (e) standardized root mean square residual (SRMR) value <.08 ( $\mathrm{Hu}$ and Bentler 1999); item loadings of at least .40 (Matsunaga, 2010), and $\chi^{2}$ fit statistics.

To address Aim 2, we tested measurement invariance of gender and PTSD diagnosis using multiple groups models for each grouping factor. We tested for configural, metric and scalar invariance across groups, and allowed for partial invariance when necessary. Rescaled $-2 \log$ 
likelihood ( $-2 \mathrm{LL})$ tests were used to compare nested models to determine which model best fits the data and whether more restrictive levels of invariance were supported. After establishing measurement invariance, relationships with several convergent and divergent measures were examined for the total sample, and in each group, we tested whether the correlations differed across groups between the DRDI and external measures using Steiger's $Z$ tests (Aim 3). For purposes of the present study, correlations of $.1, .3$ and .5 were considered small, moderate and large. To examine Aim 4, we ran a series of hierarchical regressions with each convergent measure as an outcome. We entered all the other convergent measures in step 1 and entered DRDI scores in step 2 to see if it significantly increased $R^{2}$ over and above all the other measures.

\section{Study sample 1}

Data collected as part of Study 1 were used to establish the initial factor structure of the DRDI. Participants for the DRDI factor structure validation were collected through a Department of Psychology research participation system in a public university located in the Southern United States. Inclusion criteria required participants to be current undergraduate students and able to speak, read and write English and have no self-reported visual (corrected vision or glasses is adequate) or auditory problems. Each participant was completed an anonymous online survey that began with an information sheet and consent document. The study protocol and data collected as part of Phase 1 were reviewed and approved by the Institutional Review Board at the University of Texas at San Antonio. The demographics of the total sample are outlined in Table 2. Considering the frequency at which individuals report trauma exposure, we did not pre-screen for a history of trauma exposure, or exclude participants from analysis when they endorsed 'no experienced traumas'. Indeed, most of the participants $(94.8 \%)$ in sample 1 reported a history of lifetime trauma exposure with motor vehicle accidents (45.4\%), and the experiencing of a natural disaster (30.4\%) being the most commonly reported; $13.7 \%$ of the participants in sample 1 met the criteria for PTSD based on a Posttraumatic Stress Disorder Checklist-5 (PCL-5) score of 33 or higher.

\section{Study sample 2}

Participants for Sample $2(n=249)$ were collected through targeted sampling via the Qualtrics data collection pool (Qualtrics, 2017). Purposive sampling for two distinct groups (group 1: meets criteria for PTSD diagnosis; group 2: did not meet criteria PTSD diagnosis) was conducted to ensure that an appropriate number of individuals with PTSD were recruited. Inclusion criteria were the same for each group with a notable exception for group 1 (PTSD group), which included a requirement for individuals to have endorsed experiencing a traumatic event and subsequently have screened positive for PTSD symptoms based on a PCL-5 cut-off score of 33 or greater (Bovin et al., 2016). Inclusion criteria for both groups required individuals to be at least 18 years of age and capable of completing a survey without assistance from another individual. No additional exclusion criteria were established for the non-PTSD group. Each participant completed an anonymous online survey that began with an information sheet and consent document. The survey consisted of a sociodemographic measure that included questions about the participant's sex, age and marital status as well as seven additional measures. Phase 2 of the present study was also reviewed and approved by the Institutional Review Board at the University of Texas at San Antonio (protocol no. 19-074).

The composition of sample 2 is outlined in Table 2. Most of the participants (84.8\%) in sample 2 reported a history of lifetime trauma exposure with childhood trauma (28.3\%), and the experiencing of a sexual assault (22.0\%) being the most commonly reported. Overall, sample 2 was approximately evenly split by gender (52.6\% male) and PTSD status, with $49.4 \%$ of participants screening positive for PTSD (52.8\% male). $\chi^{2}$ comparisons showed the PTSD/no-PTSD groups significantly differed 
Table 2. Sample demographics

\begin{tabular}{|c|c|c|c|}
\hline Demographic & & $\begin{array}{l}\text { Sample } 1 \\
(n=401)\end{array}$ & $\begin{array}{c}\text { Sample } 2 \\
(n=249)\end{array}$ \\
\hline \multirow[t]{2}{*}{ Sex } & Male & $129(32.1 \%)$ & $131(52.6 \%)$ \\
\hline & Female & $272(67.9 \%)$ & $118(47.4 \%)$ \\
\hline Age & 1979-1984 & $1(0.2 \%)$ & $69(27.7 \%)$ \\
\hline \multirow{4}{*}{ (birth years) } & 1985-1989 & $1(0.2 \%)$ & $56(22.5 \%)$ \\
\hline & 1990-1995 & $11(2.7 \%)$ & $38(15.3 \%)$ \\
\hline & $1996-2001$ & $385(96 \%)$ & $55(17.1 \%)$ \\
\hline & Other & $3(0.6 \%)$ & $34(13.7 \%)$ \\
\hline \multirow[t]{2}{*}{ Marital status } & Married & $399(99.5 \%)$ & $105(42.2 \%)$ \\
\hline & Not married & $2(0.5 \%)$ & $141(57.8 \%)$ \\
\hline \multirow[t]{6}{*}{ Race/ethnicity } & White & $268(66.8 \%)$ & $168(67.5 \%)$ \\
\hline & Black or African American & $65(16.2 \%)$ & $32(12.9 \%)$ \\
\hline & American Indian or Alaska Native & $6(1.5 \%)$ & $2(0.8 \%)$ \\
\hline & Asian & $22(5.5 \%)$ & $11(4.43 \%)$ \\
\hline & Hispanic & $35(8.7 \%)$ & $10(4.0 \%)$ \\
\hline & Other/unknown & $5(1.3 \%)$ & $26(10.4 \%)$ \\
\hline \multirow[t]{8}{*}{ Education } & Less than high school diploma & - & $6(2.4 \%)$ \\
\hline & High school graduate (or GED) & $217(54.1 \%)$ & $37(14.9 \%)$ \\
\hline & Some college but no degree & $166(41.4 \%)$ & $69(27.7 \%)$ \\
\hline & $\begin{array}{l}\text { Associate degree in college } \\
\text { (2-year) }\end{array}$ & $17(4.2 \%)$ & $33(13.3 \%)$ \\
\hline & $\begin{array}{l}\text { Bachelor's degree in college } \\
\text { (4-year) }\end{array}$ & $1(0.2 \%)$ & $58(23.3 \%)$ \\
\hline & Master's degree & - & $29(11.6 \%)$ \\
\hline & Doctoral degree & - & $8(3.2 \%)$ \\
\hline & Professional degree (JD, MD) & - & $9(3.6 \%)$ \\
\hline \multirow[t]{6}{*}{ Military pay grade } & $E-1$ to $E-4$ & - & $38(15.3 \%)$ \\
\hline & $\mathrm{E}-5$ to $\mathrm{E}-6$ & - & $28(11.2 \%)$ \\
\hline & $\mathrm{E}-7$ to $\mathrm{E}-9$ & - & $26(10.4 \%)$ \\
\hline & O-1 (WO1) to 0-3 (CW3) & - & $14(5.6 \%)$ \\
\hline & O-4 (CW4) to 0-6 (CW5) & - & $11(4.4 \%)$ \\
\hline & Not applicable/unknown & $401(100 \%)$ & $132(53.0 \%)$ \\
\hline \multirow[t]{5}{*}{ Branch of service } & Army & - & $91(36.5 \%)$ \\
\hline & Air Force & - & $7(2.8 \%)$ \\
\hline & Navy & - & $14(5.6 \%)$ \\
\hline & Marine Corps & - & 11 (4.4\%) \\
\hline & Not applicable/unknown & $401(100 \%)$ & $126(50.6 \%)$ \\
\hline
\end{tabular}

Military pay grades include enlisted service members (junior enlisted E-1 to E-4; non-commissioned officers E-5 to E-9) as well as commissioned officers (0-1 to 0-6) and Warrant Officer (WO) 1 to Chief Warrant Officer (CW) 5 .

only on age $\left(\chi^{2}[4,249]=15.95, p=.01\right)$ with participants aged $18-22$ years under-represented in PTSD diagnoses relative to expectations based on chance. Likewise, males and females were also found to differ in terms of age $\left(\chi^{2}[4,249]=10.32, p=.01\right)$, with an over-representation of younger males as well as males who did not provide an age.

\section{Measures}

Each measure used as part of this study was selected from the Consortium to Alleviate PTSD common data elements or used a publicly available analog comparison (see Barnes et al., 2019). Additional measures that have been previously identified as related to resilience were selected to further elucidate on the validity.

\section{Posttraumatic Stress Disorder Checklist-5}

The Posttraumatic Stress Disorder Checklist-5 (PCL-5) is a self-administered 20-item measure that assesses DSM-5 symptoms of PTSD (Bovin et al., 2016) with excellent psychometric 
properties (Cronbach's $\alpha=.96$; test-re-test=.84). The PCL-5 accounts for each symptom of PTSD within its 20 questions, but it does not assess for impairment. Participants are asked to rate the impact of an event as rated by severity on a scale ranging from 0 (indicating no impact) to 4 (indicating extreme impact). A cut-off score of 31-33 on the PCL-5 is indicative of predicting a PTSD diagnosis based on DSM-5 criteria (Bovin et al., 2016). For the present study, coefficient $\alpha=.97$ (sample 2).

\section{Dispositional Resilience Scale-15}

The Dispositional Resilience Scale-15 (DRS-15) is a 15-item self-report measure that assesses a person's level of psychological hardiness (Bartone, 2007). Psychological hardiness is a correlate of resilience and primarily addresses elements of resilience via consideration of control, commitment and challenge. The DRS-15 has high internal reliability $(a=.82)$ and good testre-test reliability ( $r=.78$; Bartone, 2007). For the present study, coefficient $\alpha=.80$ (sample 2) for the total scale score.

\section{Brief Inventory of Psychosocial Functioning}

The Brief Inventory of Psychosocial Functioning (b-IPF) is a 7-item self-report measure that assesses PTSD-related psychosocial impairment (Bovin et al., 2018; Erb et al., 2015). Limited information exists on the psychometric validity of the b-IPF; however, initial reports are that it is a reliable and valid tool that may be used when assessing individual impairment (Bovin et al., 2018; Erb et al., 2015). For the present study, coefficient $\alpha=.79$ (sample 2).

\section{Depressive Symptom Inventory - Suicide Scale}

The Depressive Symptom Inventory - Suicide Scale (DSI-SS) is a self-administered 8-item measure that is used to detect the extent to which a person is experiencing suicidal ideation(s) (Glischinski et al., 2016). The DSI-SS scores each item on a scale ranging from zero (indicating no suicidal ideation) to three (indicating a high likelihood of suicidal ideations). When assessing suicidal ideation(s) in the general population, a recommended cut point is 2 per item (sensitivity=.89; specificity=.86; Glischinski et al., 2016). For the present study, coefficient $\alpha=.96$ (sample 2).

\section{Depression, Anxiety and Stress Scale-21}

The Depression, Anxiety and Stress Scale (DASS-21) is a 21-item self-report measure that assesses three related negative emotional states as related to depression, anxiety, and tension or stress (Norton, 2007). The DASS-21 has good internal validity for each subscale (depression: $\alpha=.83$; anxiety: $\alpha=.78$; stress: $\alpha=.87$; Norton, 2007). For the present study, coefficient $\alpha=.97$ for the total scale and .93 (depression), .91 (anxiety) and .95 (stress) for each subscale, respectively (sample 2).

\section{Intolerance of Uncertainty Scale-Short Form}

The Intolerance of Uncertainty scale - Short Form (IUS-SS) is a 12-item self-report measure that assesses notions surrounding ambiguous situations, uncertainty, and the future (Carleton et al., (2007). Participants are instructed to rate their self-evaluation of each question on a Likert scale ranging from 1 (not at all characteristic of me) to 5 (entirely characteristic of me). The IUS-SS has strong convergent validity with the full scale $(r=.94)$ (Carleton et al., 2007), and good internal consistency ( $a=.85$; Carleton et al., 2007). For the present study, coefficient $\alpha=.96$ (sample 2). 


\section{Authenticity Scale}

The Authenticity Scale (AS) is a 12-item self-report measure that assesses three components of dispositional authenticity (self-alienation, authentic living, and acceptance of external influence; Wood et al., 2008). The AS has good internal consistency (ranging from .70 to .86) and good testre-test reliability ( $r=.78$ to .91 ; Wood et al., 2008). For the present study, coefficient $\alpha=.86$ (sample 2).

\section{Results}

\section{Factor structure of the DRDI items: sample 1}

The DRDI was conceptualized as a two-dimensional scale that would predict cognitions related to recovery and dysfunction. Upon examination of the eigenvalues present in the exploratory factor analysis (EFA; sample 1), we observed that there were two clear factors present (1) 5.13 (33.12\% variance) and (2) 2.61 (48.02\% total variance). No other eigenvalue approached meaningfulness. Considering this coupled with the a priori expectation for two factors, we evaluated the model fit of unidimensional and correlated traits factor solutions. To examine this, we compared a unidimensional model with a two-factor correlated traits model through EFA, using maximum likelihood robust as the extraction method with an oblique rotation. As hypothesized, the EFA indicated that a two-factor structure was superior to the unidimensional model $(p<.001)$. The unidimensional model exhibited poor model fit per all pre-established criteria (robust $\chi^{2}[77$, $n=401]=909.63, p<.001 ; \mathrm{RMSEA}=.16 ; \mathrm{CFI}=.65 ; \mathrm{SRMR}=.13)$. Items intended to represent dysfunction cognitions loaded well (.55 to .83) on the single factor, whereas items intended to represent recovery cognitions did not (.15 to .49), indicating that these items in each group are not merely the converse of the other.

The correlated traits model provided satisfactory fit to the data (robust $\chi^{2}[64, n=401]=268.54$, $p<.001 ; \mathrm{RMSEA}=.08 ; \mathrm{CFI}=.91 ; \mathrm{SRMR}=.03$ ). The $-2 \mathrm{LL}$ test indicated that relative to the unidimensional model, the two-factor model fit significantly better $\left(\Delta \chi^{2}(13)=641.09, p<.001\right)$. Items 2, 4, 5, 8, 10, 13 and 14 loaded on what we labelled the 'Dysfunction Cognitions' subscale, and items 1, 3, 6, 7, 9, 11 and 12 loaded on what we labelled the 'Recovery Cognitions' subscale. Factor loadings for each subscale were excellent, except for items 1, 6 and 7. Given that the reliability of the Recovery subscale was high when including these items, we retained them to ensure the subscales were of equal length. Standardized factor loadings and fit statistics, for each of the compared models as well as evidence for validity, are outlined in Table 3.

\section{Sample 2}

Similar to the findings noted in sample 1, the two-factor correlated traits model provided satisfactory fit to the data (robust $\chi^{2}[76, n=249]=181.61, p<.001$; RMSEA=.07; CFI=.94; $\mathrm{SRMR}=.06$ ). Once again, the $-2 \mathrm{LL}$ test indicated that relative to the unidimensional model, the two-factor model fit significantly better $\left(\Delta \chi^{2}(1)=531.60, p<.001\right)$. In sample 2 , the two factors negatively correlated $r=-.25$, and each exhibited excellent reliability based on coefficient omega (Dysfunction=.95 and Resilience=.89). Factor loadings for each subscale were excellent (.71 to .90$)$ with a singular exception of item $6(.49)$.

\section{Invariance testing}

To address Hypothesis 2, we examined the correlated traits factor model for measurement invariance by both gender $(n=249$; males $=52.6 \%)$ and PTSD status $(n=242 ; 49.2 \%$ PTSD) in participants from sample 2 . When examining invariance by gender, the configural invariance model provided an adequate fit to the data (robust $\chi^{2}(152)=292.76, p<.001 ; \mathrm{CFI}=.92$; $\mathrm{RMSEA}=.07 ; \mathrm{SRMR}=0.07$ ) as did the metric invariance (robust $\chi^{2}(164)=314.14, p<.001$; 
Table 3. Standardized factor loadings, EFA and CFA fit statistics of competing models

\begin{tabular}{|c|c|c|c|c|c|c|}
\hline \multirow{3}{*}{$\begin{array}{l}\text { Dispositional Recovery and } \\
\text { Dysfunction Inventory item } \\
\text { no. }\end{array}$} & \multicolumn{3}{|c|}{$\begin{array}{c}\text { Sample } 1 \\
(n=401)\end{array}$} & \multicolumn{3}{|c|}{$\begin{array}{c}\text { Sample } 2 \\
(n=249)\end{array}$} \\
\hline & \multicolumn{3}{|c|}{ EFA } & \multirow{2}{*}{$\begin{array}{l}\text { Uni-dimen- } \\
\text { sional model }\end{array}$} & \multicolumn{2}{|c|}{$\begin{array}{l}\text { Correlated traits factors } \\
\text { model }\end{array}$} \\
\hline & One-factor & \multicolumn{2}{|c|}{ Two-factor } & & Dysfunction & Recovery \\
\hline 2 & .75 & .73 & -.03 & .83 & .83 & \\
\hline 4 & .74 & .71 & -.05 & .90 & .90 & \\
\hline 5 & .70 & .69 & -.04 & .89 & .89 & \\
\hline 8 & .77 & .85 & .09 & .87 & .87 & \\
\hline 10 & .83 & .74 & -.18 & .86 & .86 & \\
\hline 13 & .55 & .55 & -.01 & .81 & .81 & \\
\hline 14 & .74 & .82 & .08 & .89 & .89 & \\
\hline 1 & .15 & .09 & .51 & .12 & & .71 \\
\hline 3 & .32 & .00 & .67 & .24 & & .76 \\
\hline 6 & .16 & .11 & .54 & .05 & & .49 \\
\hline 7 & .13 & .14 & .54 & .17 & & .74 \\
\hline 9 & .35 & .01 & .75 & .21 & & .78 \\
\hline 11 & .49 & -.18 & .65 & .34 & & .80 \\
\hline 12 & .41 & -.12 & .62 & .28 & & .83 \\
\hline $\operatorname{MLR} \chi^{2}$ & 909.63 & \multicolumn{2}{|c|}{$268.54^{\star}$} & 703.96 & \multicolumn{2}{|c|}{$181.61^{\star}$} \\
\hline d.f. & 77 & \multicolumn{2}{|c|}{64} & 76 & \multicolumn{2}{|c|}{76} \\
\hline $\mathrm{CFI}$ & .65 & \multicolumn{2}{|c|}{.91} & .62 & \multicolumn{2}{|c|}{.94} \\
\hline RMSEA [90\% Cl] & $.16[.15-.17]$ & \multicolumn{2}{|c|}{$.08[.07-.10]$} & $.18[.17-.20]$ & \multicolumn{2}{|c|}{$.07[.06-.09]$} \\
\hline SRMR & .13 & \multicolumn{2}{|c|}{.03} & .22 & \multicolumn{2}{|c|}{.06} \\
\hline Mean $(S D)$ & - & $\begin{array}{r}16.94 \\
(8.65\end{array}$ & $33.64(7.34)$ & - & $23.73(13.37)$ & $33.84(9.61)$ \\
\hline
\end{tabular}

*Statistically different $(p<.001)$ from previous model. In the two correlated factors model, the correlation between the two factors was $r=-.252$ (sample 2). CFI, robust comparative fit index; $\mathrm{Cl}$, confidence interval; d.f., degrees of freedom; EFA, exploratory factor analysis; MLR, maximum likelihood robust estimator; RMSEA, root mean square error of approximation; SRMR, standardized root mean squared residual.

$\mathrm{CFI}=.92 ; \mathrm{RMSEA}=.08 ; \mathrm{SRMR}=0.07)$ and scalar invariance (robust $\chi^{2}(176)=335.94, p<.001$; $\mathrm{CFI}=.91 ; \mathrm{RMSEA}=.08 ; \mathrm{SRMR}=0.08)$ models. Rescaled $\chi^{2}$ difference tests showed that metric $\left(\Delta \chi^{2}(12)=20.81, p>.05\right)$, and scalar invariance $\left(\Delta \chi^{2}(12)=21.06, p=.05\right)$ were established across all the items.

With respect to invariance by PTSD status (e.g. individuals scoring $<33$ compared with 33 or greater on the PCL-5), the configural invariance model provided an adequate fit to the data (robust $\left.\chi^{2}(152)=248.59, p<.001 ; \mathrm{CFI}=.94 ; \mathrm{RMSEA}=.07 ; \mathrm{SRMR}=0.06\right)$ as did the metric invariance model (robust $\chi^{2}(164)=261.01, p<.001$; CFI=.93; RMSEA=.07; SRMR=0.07). The scalar invariance model did not provide an adequate fit (robust $\chi^{2}(177)=340.25, p<.001$; $\mathrm{CFI}=.89 ; \mathrm{RMSEA}=.08 ; \mathrm{SRMR}=0.11)$. Rescaled $\chi^{2}$ difference tests showed that metric invariance was established across all the items $\left(\Delta \chi^{2}(12)=10.27, p=.59\right)$, but scalar invariance was not $\left(\Delta \chi^{2}(13)=87.68, p<.001\right)$. Accordingly, we tested for partial scalar invariance and were able to achieve it by allowing the intercept for item 5 to vary across PTSD status $\left(\Delta \chi^{2}\right.$ $(20)=23.73, p<.25)$.

\section{Convergent and divergent validity of the DRDI}

In support of Hypothesis 3, all correlations were in the expected directions (see Tables 4 and 5). Specifically, the Recovery subscale was found to positively correlate with the DRS-15 total (and subscales) score, and the Authenticity Scale $(p<.001)$ and was negatively correlated with the DASS-21 subscales for Anxiety and Depression ( $p$ values $=.009$ and .002 , respectively). Conversely, the Dysfunction subscale was found to positively, strongly correlate with the PCL-5, 
Table 4. Zero order correlations and Steiger's $Z$ differences by gender status on the Dispositional Recovery and Dysfunction Inventory and examined constructs

\begin{tabular}{|c|c|c|c|c|c|c|c|c|}
\hline \multirow[b]{2}{*}{ Measure } & \multicolumn{3}{|c|}{$\begin{array}{c}\text { DRDI } \\
\text { Recovery subscale }\end{array}$} & \multirow[b]{2}{*}{$\begin{array}{l}\text { Group differences } \\
\text { ( } z \text { value) }\end{array}$} & \multicolumn{3}{|c|}{$\begin{array}{c}\text { DRDI } \\
\text { Dysfunction subscale }\end{array}$} & \multirow[b]{2}{*}{$\begin{array}{c}\text { Group differences } \\
\text { ( } z \text { value })\end{array}$} \\
\hline & Full sample & $\begin{array}{c}\text { Male } \\
(n=131)\end{array}$ & $\begin{array}{l}\text { Female } \\
(n=118)\end{array}$ & & Full sample & $\begin{array}{c}\text { Male } \\
(n=131)\end{array}$ & $\begin{array}{l}\text { Female } \\
(n=118)\end{array}$ & \\
\hline AS & $.307^{\star \star \star}$ & $.252^{\star \star}$ & $.395^{\star \star}$ & -1.25 & $-.607^{\star \star}$ & $-.702^{\star \star}$ & $-.492^{\star \star}$ & $-2.59^{\star \star}$ \\
\hline IUS-SS & -.074 & .052 & $-.231^{\star}$ & $2.24^{\star}$ & $.656^{\star \star}$ & $.717^{\star \star}$ & $.591^{\star \star}$ & $1.73^{\star}$ \\
\hline DSSI-SS & -.047 & -.023 & -.144 & 0.95 & $.549^{\star \star}$ & $.533^{\star \star}$ & $.616^{\star \star}$ & -.097 \\
\hline b-IPF & .075 & .056 & .130 & -0.58 & $-.671^{\star \star}$ & $-.709^{\star \star}$ & $-.629^{\star \star}$ & -1.13 \\
\hline DASS-21 & -.124 & -.077 & $-.208^{\star}$ & 1.04 & $.808^{\star \star}$ & $.855^{\star \star}$ & $.755^{\star \star}$ & $2.26^{\star}$ \\
\hline DASS-21-A & $-.164^{\star \star}$ & -.121 & $-.231^{*}$ & 0.89 & $.722^{\star \star}$ & $.716^{\star \star}$ & $.731^{\star \star}$ & -.025 \\
\hline DASS-21-S & -.025 & .075 & -.066 & 1.09 & $.673^{\star \star}$ & $.741^{\star \star}$ & $.592^{\star \star}$ & $2.12^{\star}$ \\
\hline DASS-21-D & -.195 & -.143 & $-.302^{\star \star}$ & 1.31 & $.779^{\star \star}$ & $.833^{\star \star}$ & $.720^{\star \star}$ & $2.26^{\star}$ \\
\hline DRS-15 & $.602^{\star \star}$ & $.586^{\star \star}$ & $.604^{\star \star}$ & -0.22 & $-.671^{\star \star}$ & $-.570^{\star \star}$ & $-.496^{\star \star}$ & -0.81 \\
\hline DRS-15-CM & $.559^{\star \star}$ & $.552^{\star \star}$ & $.552^{\star \star}$ & 0.00 & $-.552^{\star \star}$ & $-.515^{\star \star}$ & $-.600^{\star \star}$ & 0.96 \\
\hline DRS-15-CH & $.273^{\star \star}$ & $.261^{\star *}$ & $.256^{\star \star}$ & 0.04 & $-.359^{\star \star}$ & $-.428^{\star \star}$ & $-.286^{\star \star}$ & -1.27 \\
\hline DRS-15-CO & $.576^{\star \star}$ & $.569^{\star \star}$ & $.575^{\star \star}$ & -0.07 & $-.337^{\star \star}$ & $-.421^{\star \star}$ & $-.249^{\star \star}$ & -1.51 \\
\hline PCL-5 & -0.70 & .042 & -.217 & -0.98 & $.558^{\star \star}$ & $.706^{\star \star}$ & $.381^{\star \star}$ & $-1.94^{\star}$ \\
\hline
\end{tabular}

${ }^{\star *}$ Bonferroni corrected alpha at $p<.017$; ${ }^{*}$ significance of $p<.05$ for $z$ scores. All data in this table are from sample 2. DRDI, Dispositional Recovery and Dysfunction Inventory; AS, Authenticity Scale; IUS-SS, Intolerance of Uncertainty Scale - Short Form; DSI-SS, Depressive Symptom Inventory - Suicide Scale; b-IPF, Brief Inventory of Psychosocial Functioning; DASS-21, Depression, Anxiety, and Stress Scale; DASS-21-A, Anxiety subscale; DASS-21-S, Stress subscale; DASS-21-D, Depression subscale; DRS-15, Dispositional Resilience Scale-15; DRS-15-CM, Commitment subscale; DRS-15-CH, Challenge subscale; DRS-15-CO, Control subscale; PCL-5, Posttraumatic Stress Disorder Checklist-5.

DASS-21, DSSI-SS and the IUS-SS ( $p$ values <.001), and negatively correlate with the Authenticity Scale as well as the DRS-15 and all three subscales $(p$ values $<.001)$. Tables 4 and 5 provide an overview of the zero-order correlations amongst each measure used in the present study as well as the correlations stratified by gender (Table 4) and PTSD status (Table 5), along with Steiger's $Z$ tests of the differences between the group's correlations.

Data from sample 2 show that the strength of the observed relationships on the Recovery subscale significantly differed amongst individuals with and without PTSD on measures related to authenticity, depression, anxiety, and stress $(p<.001)$, intolerance of uncertainty $(p=.009)$, as well as psychosocial functioning $(p=.001)$. Conversely, the strengths of the observed relationships between the Recovery subscale and examined measures showed males and females differed only on a measure related to intolerance of uncertainty $(p=.01)$. When examining the strength of the relationships on the Dysfunction subscale and other examined measures, non-significant differences amongst the participants with and without PTSD were observed on all scales. Conversely, the strength of the relationships between the Dysfunction subscale and other examined measures showed that males and females differed on measures related to authenticity $(p=.002)$, intolerance of uncertainty $(p=.04)$, as well as the DASS-21 total score $(p=.01)$.

\section{Predictive validity of the DRDI}

To test Hypothesis 4, we ran a series of hierarchical regressions predicting the various study measures using all other measures in step 1 and adding DRDI subscale scores in step 2. The results are summarized herein and expanded in Tables S1 and S2 in the Supplementary material. To reduce the potential for error related to multiple comparisons, Bonferroni corrected $p$-values were considered significant at $p<.006$. Results indicated that adding both DRDI subscales increased the $R^{2}$ related to the assessment of depression, anxiety and stress $(p<.001)$, and psychological hardiness (Dysfunction $p=.002$; Recovery $p<.001$ ). 
Table 5. Zero order correlations and Steiger's Z differences by PTSD status on the Dispositional Recovery and Dysfunction Inventory and examined constructs

\begin{tabular}{|c|c|c|c|c|c|c|c|c|}
\hline \multirow[b]{2}{*}{ Measure } & \multicolumn{3}{|c|}{$\begin{array}{c}\text { DRDI } \\
\text { Recovery subscale }\end{array}$} & \multirow[b]{2}{*}{$\begin{array}{c}\text { Group differences } \\
\text { ( } z \text { value })\end{array}$} & \multicolumn{3}{|c|}{$\begin{array}{c}\text { DRDI } \\
\text { Dysfunction subscale }\end{array}$} & \multirow[b]{2}{*}{$\begin{array}{c}\text { Group differences } \\
\text { ( } z \text { value })\end{array}$} \\
\hline & Full sample & $\begin{array}{c}\text { PTSD } \\
(n=123)\end{array}$ & $\begin{array}{l}\text { No PTSD } \\
(n=126)\end{array}$ & & Full sample & $\begin{array}{c}\text { PTSD } \\
(n=123)\end{array}$ & $\begin{array}{l}\text { No PTSD } \\
(n=126)\end{array}$ & \\
\hline AS & $.307^{t}$ & .024 & $.558^{t}$ & $-4.72^{\star \star}$ & $-.607^{t}$ & $-.476^{t}$ & $-.619^{t}$ & 1.60 \\
\hline IUS-SS & -.074 & .147 & -.153 & $-2.36^{\star \star}$ & $.656^{t}$ & $.500^{t}$ & $.511^{t}$ & -0.01 \\
\hline DSSI-SS & -.047 & .041 & -.084 & 0.98 & $.549^{t}$ & $.447^{t}$ & $.463^{t}$ & 0.16 \\
\hline b-IPF & .075 & -.121 & .137 & $-2.88^{\star}$ & $-.671^{t}$ & $-.554^{t}$ & $-.509^{t}$ & -0.49 \\
\hline DASS-21 & -.047 & .201 & $-.380^{t}$ & $4.71^{\star \star}$ & $.808^{t}$ & $.697^{t}$ & $.757^{t}$ & -0.99 \\
\hline DASS-21-A & $-.164^{t}$ & .185 & $-.361^{t}$ & $4.41^{\text {** }}$ & $.722^{t}$ & $.579^{t}$ & $.682^{t}$ & -1.34 \\
\hline DASS-21-S & -.025 & $.298^{t}$ & -.202 & $3.99^{\star \star}$ & $.673^{t}$ & $.537^{t}$ & $.550^{t}$ & -0.14 \\
\hline DASS-21-D & -.195 & .037 & $-.393^{t}$ & $3.53^{\star \star}$ & $.779^{t}$ & $.696^{t}$ & $.724^{t}$ & -0.44 \\
\hline DRS-15 & $.602^{t}$ & $.555^{t}$ & $.636^{t}$ & -0.98 & $-.671^{t}$ & $-.440^{t}$ & $-.547^{t}$ & 1.11 \\
\hline DRS-15-CM & $.559^{t}$ & $.529^{t}$ & $.577^{t}$ & -0.54 & $-.552^{t}$ & $-.473^{t}$ & $-.547^{t}$ & 0.78 \\
\hline DRS-15-CH & $.273^{t}$ & $.221^{t}$ & $.298^{t}$ & -0.64 & $-.359^{t}$ & $-.317^{t}$ & $-.355^{t}$ & 0.33 \\
\hline DRS-15-CO & $.576^{t}$ & $.498^{t}$ & $.634^{t}$ & -1.57 & $-.337^{t}$ & -.200 & $-.412^{t}$ & 1.83 \\
\hline
\end{tabular}

${ }^{t}$ Bonferroni corrected alpha at $p<.017$; ${ }^{* *}$ significance of $p<.01$ and ${ }^{*} p<.05$ for $z$ scores. All data in this table are from sample 2 .

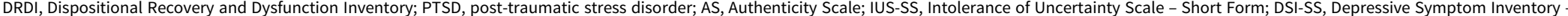

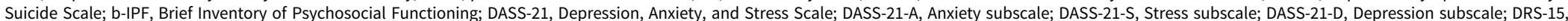

Dispositional Resilience Scale-15; DRS-15-CM, Commitment subscale; DRS-15-CH, Challenge subscale; DRS-15-CO, Control subscale. 


\section{Discussion}

The present study described the development and psychometric validation of a measure of dispositional recovery and dysfunction. The DRDI consists of 14 items (e.g. I often feel undesirable), in which participants rated their overall functioning on a 7-point scale rated from 1 (not at all like me) to 7 (completely like me). In all, we found evidence of validity for the DRDI in the following results: (1) significant correlations between each comparison measure were observed, in the expected directions, (2) the two factors were correlated with each other in the expected direction, and (3) the measure showed itself to be invariant across gender and by PTSD status. The results from the CFA found the DRDI to be a multidimensional measure that is best represented as a two-factor correlated traits model. Additionally, each factor presented with strong factor loadings and reliable subscale coefficients. In support of previous research that has shown that the resilience construct is related to both pathology and positive life experiences, this preliminary validation of the DRDI provides evidence for supporting recovery and dysfunction cognitions as related to a range of positive and negative psychological constructs that are known to impact individuals' health-related quality of life.

When comparing the DRDI with proposed measures of convergent and divergent validity, consistent patterns emerged. Specifically, individuals who reported high levels of recovery also reported higher levels of psychological hardiness and reduced levels of anxiety and depression. This is in line with previous examinations of the resilience construct in military personnel (Johnson et al., 2011) but contrary to the findings reported in the initial validation of the CD-RISC (Connor and Davidson, 2003). Connor and Davidson (2003) found resilience to be inversely correlated with perceived stress, whereas the present study found the recovery subscale to be uncorrelated with stress. Conversely, elements of cognitive dysfunction were strongly correlated with perceived stress, thus providing evidence for the need to assess for recovery and dysfunction simultaneously.

Interestingly, high levels of dispositional recovery were found to be present with mixed results surrounding pathological concerns. Specifically, the DRDI provides additional evidence that elements of resilience are negatively related to sentiments of anxiety and depression. Conversely, however, dispositional recovery was found to be unrelated to concurrent PTSD symptoms. This finding partially contrasts with the published literature which shows that resilience should be a protective factor against PTSD symptoms (Lee et al., 2014; Stratta et al., 2015; Wingo et al., 2010). Taken together, these findings highlight the importance of the dyadic theoretical nature under which the DRDI was developed and serve to underscore the theoretical underpinning that resilience may be measured in numerous ways. Specifically, recovery throughout psychotherapy may be a part of resilience that is not well understood in the current literature. As such, we believe that further examination of the construct is warranted.

When considering the dysfunction subscale, the present data indicate that the presence of dispositional cognitive dysfunction may be a risk factor for the maintenance of negative behavioural health, specifically in trauma-exposed individuals. The present findings show that individuals with high scores on the Dysfunction subscale reported significantly lower levels of psychological hardiness and psychosocial functioning as well as higher levels of PTSD symptoms, stress, anxiety, depression, suicidal ideations, and intolerance of uncertainty. In addition, the small negative correlation between the two subscales indicates the DRDI is assessing two distinct and functionally independent dimensions that are likely to be beneficial to clinicians when assessing a patient's progress in therapy. Thus, it seems that traumaexposed individuals who are experiencing slow recovery may also be experiencing a reduction in personal resources and thereby increases in subjective levels of dysfunction. This is in line with the current literature which shows elements of maladaptive cognitions (e.g. rumination or catastrophic thinking) may be central elements related to pathology, specifically PTSD (Gellatly and Beck, 2016). 
This study had many noteworthy strengths. When conceptualizing this study, we thought it important to examine this scale in multiple different populations; as such, we conducted purposive sampling to ensure an approximately even split of males and females as well as individuals who were suspected to have higher levels of dysfunctional cognitions (e.g. those with PTSD). We believe we satisfactorily accomplished this. Specifically, sample 2 was unique in its nearly even split on sex and allowed us to show full measurement invariance across gender, indicating that the DRDI can be interpreted equally for both men and women. Finally, the present study has provided preliminary support showing the DRDI to be sensitive to a range of psychological concerns, and that it accounts for unique variance in the assessment of many disorders over and above current scales.

Despite the promising findings of the DRDI, the present study does present with limitations that warrant further discussion. As the first study to utilize the DRDI, this study was primarily exploratory and conducted to present the measure for future research. In consideration of this, future studies should further expand the construct and predictive validity of the DRDI using other well-established assessments such as the Posttraumatic Growth Inventory (Tedeschi and Calhoun, 1996) or the Posttraumatic Cognitions Inventory (Foa et al., 1999). A secondary limitation of the present study is that the data were cross-sectional, thereby limiting the ability to examine the temporal validity of the DRDI. Additionally, we were unable to recruit across a wide range of ethnicities; future studies that utilize the DRDI should consider examining its factor structure in more diverse samples and work to establish cross-cultural validity. Additionally, the invariance testing for PTSD relied on the sole utilization of self-report to determine an individual's PTSD symptoms. As individuals with PTSD are known to experience memory issues (Danckwerts and Leathem, 2003; Hart et al., 2008), it seems plausible that some of the recorded symptoms and events may have been under- or over-reported in some instances. Finally, PTSD symptoms are continuous, thus future studies would benefit from further elucidating on what invariance testing between trauma-exposed individuals who develop PTSD versus those who are trauma-exposed but do not develop PTSD might theoretically mean. Conversely, the DRDI was developed through the input of individuals with expertise in trauma-focused research and/or therapy and did not specifically include trauma survivors in the focus group or during follow-on construct refinement. In order to ensure that operational definitions of target constructs are applicable as intended, we recommend that where possible, future studies should consider including the target populations in their scale development process. Furthermore, an extension of the present study could also benefit from validating these findings in a population of individuals who have been clinically diagnosed with PTSD as well as in conjunction with implicit measures to assess for cognitive dysfunction outside of an individual's awareness.

\section{Conclusions and future directions}

The DRDI has multiple potential applications in social, health and clinical psychology. For researchers, it provides a starting point to examine which elements of psychological functioning are deficient in a target population, or which elements may require targeted intervention to increase the health-related quality of life of individuals. For clinicians who are 'stuck' on what to address with a patient who is not showing signs of improvement during psychotherapy, the DRDI may present with a novel approach to better understand their concerns. Specifically, the DRDI presents with self-assessments of distinct topics (e.g. desirability, perceived worth, shame, and impairment) that a therapist may utilize at baseline as well as through therapy to assess for the potential for recovery while stimulating new avenues of conversation and thereby the potential for behaviour change and healing. In summary, the DRDI is a valid measure that is sensitive to a range of psychiatric concerns and the preliminary evaluation of the DRDI provides evidence that it is a brief and comprehensive 
measure that is psychometrically valid and provides researchers and clinicians with opportunities to examine a broad range of elements that comprise psychological functioning, specifically surrounding an individual's ability to recover following trauma.

Acknowledgements. None.

Financial support. This research did not receive any specific grant from funding agencies in the public, commercial, or notfor-profit sectors.

Conflicts of interest. The authors have no conflicts of interest to report. The views and information presented are those of the authors and do not represent the official position of the U.S. Army Medical Center of Excellence, the U.S. Army Training and Doctrine Command, or the Departments of Army, Department of Defense, of U.S. Government.

Ethics statement. The current study adhered to the Ethical Principles of Psychologists and Code of Conduct as set out by the BABCP and BPS. The two studies utilized for this study were reviewed and approved by a local Institution Review Board.

Data availability statement. The data that support the findings of this study are available from the corresponding author (B.A.M.) upon reasonable request.

Supplementary material. To view supplementary material for this article, please visit: https://doi.org/10.1017/ S1352465821000230

\section{References}

Aiena, B., Buchanan, E., Smith, C., \& Schulenberg, S. (2016). Meaning, resilience, and traumatic stress after the Deepwater Horizon oil spill: a study of Mississippi coastal residents seeking mental health services. Journal of Clinical Psychology, 72, 1264-1278. https://doi.org/10.1002/jclp.22232

American Psychiatric Association (2013). Diagnostic and Statistical Manual of Mental Disorders (5th edn). Washington, DC, USA.

Barnes, J. B., Presseau, C., Jordan, A. H., Kline, N. K., Young-McCaughan, S., Keane, T. M., Peterson, A. L., Litz, B. T., and the Consortium to Alleviate PTSD (2019). Common data elements for military-related PTSD research applied in the Consortium to Alleviate PTSD. Military Medicine, 184, e218-e226. https://doi.org/10.1093/milmed/usy226

Bartone, P. (2007). Test-retest reliability of the Dispositional Recovery Scale-15, a brief hardiness scale. Psychological Reports, 101, 943-944. doi: 10.2466/pr0.101.3.943-944

Benjet, C., Bromet, E., Karam, E., Kessler, R., McLaughlin, K., Ruscio, A., . . \& Koenen, K. (2016). The epidemiology of traumatic event exposure worldwide: Results from the World Mental Health Survey Consortium. Psychological Medicine, 46, 327-343. doi: 10.1017/S0033291715001981

Bezdjian, S., Burchett, D., Schneider, K., Baker, M., \& Garb, H. (2015). Multidimensional Suicide Inventory-28 (MSI-28) within a sample of military basic trainees: an examination of psychometric properties. Military Psychology, 27, 325-334. https://doi.org/10.1037/mil0000090

Bonanno, A. (2004). Loss, trauma, and human resilience: have we underestimated the human capacity to thrive after extremely aversive events? American Psychologist, 59, 20-28. doi: 10.1037,0003-066X.59.1.20

Bonanno, G. A., Westphal, M., \& Mancini, A. D. (2011). Resilience to loss and potential trauma. Annual Review of Clinical Psychology, 7, 511-535. doi: 10.1146/annurev-clinpsy-032210-104526

Bonanno, G. A., Wortman, C. B., Lehman, D. R., Tweed, R. G., Haring, Sonnega, J., . . \& Nesse, R. M. (2002). Resilience to loss and chronic grief: a prospective study from preloss to 18-months postloss. Journal of Personality Social Psychology, 83, 1150-1164. doi: 10.1037//0022-3514.83.5.1150

Bovin, M. J., Black, S. K., Rodriguez, P., Lunney, C. A., Kleiman, S. E., Weathers, F. W., ... \& Marx, B. P. (2018). Development and validation of a measure of PTSD-related psychosocial functional impairment: the Inventory of Psychosocial Functioning. Psychological Services, 15, 216-229. doi: 10.1037/ser0000220

Bovin, M. J., Marx, B. P., Weathers, F. W., Gallagher, M. W., Rodriguez, P., Schnurr, P. P., \& Keane, T. M. (2016). Psychometric properties of the PTSD Checklist for Diagnostic and Statistical Manual of Mental Disorders-Fifth Edition (PCL-5) in veterans. Psychological Services, 28, 1379-1391. doi: 10.1037/pas0000254

Broekman, B. (2011). Stress, vulnerability and resilience, a developmental approach. European Journal of Psychotraumatology, 2. https://doi.org/10.3402/ejpt.v2i0.7229

Carleton, R., Norton, P., \& Asmundson, G. (2007). Fearing the unknown. A short version of the Intolerance of Uncertainty Scale. Journal of Anxiety Disorders, 21, 105-117.

Chmitorz, A., Wenzel, M., Stieglitz, R.-D., Kunzler, A., Bagusat, C., Helmreich, I., ... \& Tüscher, O. (2018). Brief Resilience Scale-German version. PsycTESTS Dataset. doi: 10.1037/t70058-000 
Connor, K., \& Davidson, J. (2003). Development of a new resilience scale: the Connor-Davidson Resilience Scale (CD-RISC). Depression and Anxiety, 18, 76-82. https://doi.org/10.1002/da.10113

Danckwerts, A., \& Leathem, J. (2003). Questioning the link between PTSD and cognitive dysfunction. Neuropsychology Review, 13, 221-235. https://doi.org/10.1023/b:nerv.0000009485.76839.b7

deRoon-Cassini, T. A., Mancini, A. D., Rusch, M. D., \& Bonanno, G. A. (2010). Psychopathology and resilience following traumatic injury: a latent growth mixture model analysis. Rehabilitation Psychology, 55, 1-11. doi: 10.1037/a0018601

Di Fabio, A., \& Palazzeschi, L. (2015). Hedonic and eudaimonic well-being: the role of resilience beyond fluid intelligence and personality traits. Frontiers in Psychology, 6, 1367. https://doi.org/10.3389/fpsyg.2015.01367

Erb, S. E., Kearns, J., Bovin, M. J., Black, S., Annunziata, A., Marx, B. P., \& Keane, T. M. (2015). Psychometric properties of the Brief Inventory of Psychosocial Functioning. Poster presented at the 31st annual meeting of the International Society for Traumatic Stress Studies, New Orleans, LA, in November 2015.

Foa, E. B., Ehlers, A., Clark, D. M., Tolin, D. F., \& Orsillo, S. M. (1999). The Posttraumatic Cognitions Inventory (PTCI): development and validation. Psychological Assessment, 11, 303-314. https://doi.org/10.1037/1040-3590.11.3.303

Gellatly, R., \& Beck, A. (2016). Catastrophic thinking: a transdiagnostic process across psychiatric disorders. Cognitive Therapy \& Research, 40, 441-452. https://doi.org/10.1007/s10608-016-9763-3

Glischinski, M., Teismann, T., Prinz, S., Gebhauer, J. E., \& Hirschfeld, G. (2016). Depressive Symptom Inventory Suicidality Subscale: optimal cut points for clinical and non-clinical samples. Clinical Psychology and Psychotherapy, 23, 543-549. doi: 10.1002/cpp.2007

Hart, J., Kimbrell, T., Fauver, P., Cherry, B. J., Pitcock, J., Booe, L. Q., Tillman, G., \& Freeman, T. W. (2008). Cognitive dysfunctions associated with PTSD: evidence from World War II prisoners of war. Journal of Neuropsychiatry and Clinical Neurosciences, 20, 309-316. https://doi.org/10.1176/jnp.2008.20.3.309

Hu, L., \& Bentler, P. M. (1998). Fit indices in covariance structure modeling: sensitivity to underparameterized model misspecification. Psychological Methods, 3, 424-453. doi: 10.1037//1082-989x.3.4.424

Kessler, R. C., Chiu, W. T., Demler, O., \& Walters, E. E. (2005). Prevalence, severity, and comorbidity of 12-Month DSM-IV disorders in the National Comorbidity Survey Replication. Archives of General Psychiatry, 62, 617. doi: 10.1001/archpsyc. 62.6.617

Kilpatrick, D. G., Resnick, H. S., Milanak, M. E., Miller, M. W., Keyes, K. M., \& Friedman, M. J. (2013). National estimates of exposure to traumatic events and PTSD prevalence using DSM-IV and DSM-5 criteria. Journal of Traumatic Stress, 26, 537-547. doi: 10.1002/jts.21848

Lee, J. S., Ahn, Y. S. Jeong, K. S. Chae, J. H., \& Choi, K. S. (2014). Resilience buffers the impact of traumatic events on the development of PTSD symptoms in firefighters. Journal of Affective Disorders, 162, 128-133. doi: 10.1016/j.jad.2014.02.031

Lee, J. S., Choi, H., Kim, J., Nam, J., Kang, H., Koh, S., \& Oh, S. S. (2016). Self-resilience as a protective factor against development of post-traumatic stress disorder symptoms in police officers. Annals of Occupational and Environmental Medicine, 28, 58 .

Liu, D., Fairweather-Schmidt, A., Burns, R., \& Roberts, R. (2015). The Connor-Davidson Resilience Scale: establishing invariance between gender across the lifespan in a large community-based study. Journal of Psychopathology and Behavioral Assessment, 37, 340-348. https://doi.org/10.1007/s10862-014-9452-z

MacCallum, R. C., Browne, M. W., \& Sugawara, H. M. (1996). Power analysis and determination of sample size for covariance structure modeling. Psychological Methods, 1, 130-149. doi: 10.1037/1082-989x.1.2.130

Matsunaga, M. (2010). How to factor-analyze your data right: do's, don'ts, and how-to's. International Journal of Psychological Research, 3, 97-110. https://doi.org/10.21500/20112084.854

Mayordomo, T., Viguer, P., Sales, A., Satorres, E., \& Meléndez, J. (2016). Resilience and coping as predictors of well-being in adults. Journal of Psychology, 150, 809-821. https://doi.org/10.1080/00223980.2016.1203276

Meredith, L., Sherbourne, C., Gaillot, S., Hansell, L., Ritschard, H., Parker, A., \& Wrenn, G. (2011). Promoting psychological resilience in the U.S. military. Rand Health Quarterly, 1, 2.

Morote, R., Hjemdal, O., Martinez Uribe, P., Corveleyn, J., \& Morote, R. (2017). Psychometric properties of the Resilience Scale for Adults (RSA) and its relationship with life-stress, anxiety and depression in a Hispanic Latin-American community sample. PLOS One, 12, e0187954-e0187954. https://doi.org/10.1371/journal.pone.0187954

Muthén, L. K., \& Muthén, B. O. (1998-2012). Mplus User's Guide, 7th edn. Los Angeles, CA, USA: Muthén \& Muthén.

Norton, P. J. (2007) Depression Anxiety and Stress Scales (DASS-21): psychometric analysis across four racial groups. Anxiety, Stress, and Coping, 20, 253-265. doi: 10.1080/10615800701309279

Nrugham, L., Holen, A., \& Sund, A. (2010). Associations between attempted suicide, violent life events, depression, resilience and suicide by early adulthood. European Psychiatry, 25, 435-435. https://doi.org/10.1016/S0924-9338(10)70430-2

Pargament, K. T., \& Cummings J. (2010). Anchored by faith: religion as a resilience factor. In Reich, J. W., Zautra, A., \& Hall, J. S. (eds), Handbook of Adult Resilience, pp. 193-210. New York, USA: Guilford Press.

Pitts, B., Safer, M., Russell, D., \& Castro-Chapman, P. (2016). Effects of hardiness and years of military service on posttraumatic stress symptoms in U.S. army medics. Military Psychology, 28, 278-284. https://doi.org/10.1037/mil0000106 
Pulido-Martos, M., Fernández-Sánchez, M., \& Lopez-Zafra, E. (2019). Measurement invariance across gender and age in the Connor-Davidson Resilience Scale (CD-RISC) in a Spanish general population. Quality of Life Research: an International Journal of Quality of Life Aspects of Treatment, Care and Rehabilitation. https://doi.org/10.1007/s11136-019-02389-1

Qualtrics (2017). Qualtrics [software]. Provo, UT, USA.

Rapport, L., Wong, C., Hanks, R., \& Rapport, L. (2019). Resilience and well-being after traumatic brain injury. Disability and Rehabilitation, 42, 2049-2055. https://doi.org/10.1080/09638288.2018.1552327

Ristevska-Dimitrovska, G., Filov, I., Rajchanovska, D., Stefanovski, P., \& Dejanova, B. (2015). Resilience and quality of life in breast cancer patients. Open Access Macedonian Journal of Medical Sciences, 3, 727-731. https://doi.org/10.3889/oamjms. 2015.128

Rossetti, M., Tosone, A., Stratta, P., Collazzoni, A., Santarelli, V., Guadagni, E., . . \& Rossi, A. (2017). Different roles of resilience in depressive patients with history of suicide attempt and no history of suicide attempt. Revista Brasileira de Psiquiatria, 39, 216-219. https://doi.org/10.1590/1516-4446-2016-2045

Roy, A., Carli, V., \& Sarchiapone, M. (2011). Resilience mitigates the suicide risk associated with childhood trauma. Journal of Affective Disorders, 133, 591-594. https://doi.org/10.1016/j.jad.2011.05.006

Scali, J., Gandubert, C., Ritchie, K., Soulier, M., Ancelin, M.-L., \& Chaudieu, I. (2012). Measuring resilience in adult women using the 10-items Connor-Davidson Resilience Scale (CD-RISC). Role of trauma exposure and anxiety disorders. PLOS One, 7. doi: 10.1371/journal.pone.0039879

Schultze-Lutter, F., Ochsenbein, S., \& Schmidt, S. (2017). Resilience and risk, mental health and well-being: how do these concepts relate? European Psychiatry, 41, S463. https://doi.org/10.1016/j.eurpsy.2017.01.516

Smith, B. W., Dalen, J., Wiggins, K., Tooley, E., Christopher, P., \& Bernard, J. (2008). The Brief Resilience Scale: assessing the ability to bounce back. International Journal of Behavioral Medicine, 15, 194-200.

Stratta, P., Capanna, C., Dell'osso, L., Carmassi, C., Patriarca, S., Di Emidio, G., . . \& Rossi, A. (2015). Resilience and coping in trauma spectrum symptoms prediction: a structural equation modeling approach. Personality and Individual Differences, 77, 55-61. https://doi.org/10.1016/j.paid.2014.12.035

Tedeschi, R. G., \& Calhoun, L. G. (1996). The Posttraumatic Growth Inventory: measuring the positive legacy of trauma. Journal of Traumatic Stress, 9, 455-472. doi: 10.1002/jts.2490090305

Wagnild, G., \& Young, H. (1993). Development and psychometric evaluation of the Resilience Scale. Journal of Nursing Measurement, 1, 165-178.

Windle, G., Bennett, K., \& Noyes, J. (2011). A methodological review of resilience measurement scales. Health and Quality of Life Outcomes, 9. doi: 10.1186/1477-7525-9-8

Wingo, A., Wrenn, G., Pelletier, T., Gutman, A., Bradley, B., \& Ressler, K. (2010). Moderating effects of resilience on depression in individuals with a history of childhood abuse or trauma exposure. Journal of Affective Disorders, 126, 411-414. https://doi.org/10.1016/j.jad.2010.04.009

Wood, A. M., Linley, P., Maltby, A., Baliousis, J., \& Michael, J. S. (2008). The authentic personality: a theoretical and empirical conceptualization and the development of the Authenticity Scale. Journal of Counseling Psychology, 55, 385399. https://doi.org/10.1037/0022-0167.55.3.385

Zautra, A., Hall, J., \& Murray, K. (2010). Resilience: a new definition of health for people and communities. In Reich, J. W., Zautra, A., \& Hall, J. S. (eds), Handbook of Adult Resilience, pp. 3-29. New York, USA: Guilford Press.

Cite this article: Moore BA, Hale WJ, Judkins JL, and Peterson AL (2022). Development and psychometric validation of the Dispositional Recovery and Dysfunction Inventory: a tool to assess for positive and negative cognitions following trauma exposure. Behavioural and Cognitive Psychotherapy 50, 203-218. https://doi.org/10.1017/S1352465821000230 